\title{
Life histories of 9,488 bird and 4,865 mammal species
}

\author{
LARS WiTTING \\ Greenland Institute of Natural Resources, Box 570, DK-3900 Nuuk, Greenland
}

\begin{abstract}
I use 56,214 life history data to estimate equilibrium life history models for birds and mammals with body mass estimates. Missing parameters were estimated by allometric correlations at the lowest taxonomic level (genus, family, order, class) with data. The estimation is optimised to predict the existing data, with precision estimated separately for the different taxonomic levels of the estimator. This provides complete life history models for 9,488 species of birds, and 4,865 species of mammals. Each model includes estimates of metabolism, net assimilated energy, individual growth, mortality, fecundity, age of reproductive maturity, generation time, life span, home range, population density, biomass, population consumption, and a relative measure of intra-specific interactive competition, providing 387,531 parameter estimates in total.
\end{abstract}

\section{Introduction}

A life history model is essential for our ability to predict the dynamics of a natural species, and a distribution of such models across a collection of species is essential for our ability to analyse and understand evolution by natural selection. I use published life history data and the framework of Malthusian relativity (Witting 1997, 2008, 2017a,b) to estimate life history models for the majority of birds and mammals.

Malthusian relativity is a theory of evolution that uses the competition-dependent flow of energy across the interacting individuals in populations to deduce the natural selection of life histories and allometric correlations. Since Lotka (1922) published his contribution to the energetics of evolution several studies have used energy and metabolism as measures of natural selection fitness (e.g. Odum and Pinkerton 1955; Van Valen 1976; Brown et al. 1993, 2018; Humphries and McCann 2014; Burger et al. 2019). These papers describe important energetic differences between species, yet they fail to acknowledge that the true currency of natural selection fitness is the realised rates of replication among the heritable variants in populations.

The realisation of fitness is not a linear function of energy or metabolism, and nor does it produce constant relative fitness as assumed widely in classical life history theory (reviewed by e.g. Charlesworth 1994; Roff
1992, 2002; Stearns 1992; Charnov 1993; Bulmer 1994; Stearns and Hoekstra 2000). The replication rate of any individual depends not only on its own energy, life history and physiology, but also on the competitive qualities of the remaining individuals in the population, and on the density-dependent rates of competitive encounters between individuals.

Starting from the origin of replicating molecules, Malthusian relativity describes how the differential replication across the individuals in natural populations evolves with the natural selection of net energy for replication, generating population dynamic growth and density-frequency-dependent selection by interactive competition. This process is referred to as population dynamic feedback selection, with a selected increase in net energy predicting evolutionary transitions from self-replicating molecules over prokaryote-like selfreplicating cells, and larger unicells, to multicellular animals with sexual reproduction (Witting 2017a,b).

Being a theory that predicts the body mass allometries of these lifeforms from the natural selection of metabolism, net energy and mass, Malthusian relativity provides a natural starting point for the estimation of life histories by allometric correlations.

\section{$1.1 \quad$ Inter-specific extrapolations}

Inter-specific extrapolations by allometric correlations benefit from large datasets published over the past couple of decades. The most comprehensive data are for birds and mammals, where Smith et al. (2004) provides 4,361 body mass estimates for mammals, and Dunning (2007) similar estimates for more than 8,700 species of birds.

Body mass estimates are often published in allometric studied with other traits (e.g., Bonner 1965; Schoener 1968; Turner et al. 1969; Fenchel 1974; Damuth 1981, 1987; Peters 1983; Calder 1984), leading to the accumulation of basal metabolic rates for more than 700 species of mammals (McNab 2008) and 350 species of birds (McKechnie and Wolf 2004), with independent estimates of field metabolism (Hudson et al. 2013). Life history parameters on reproduction, physiological time periods, and individual growth were 
collected in large datasets by Jetz et al. (2008), De Magalhães and Costa (2009), Jones et al. (2009), and Myhrvold et al. (2015). And ecological traits like population densities and home range areas were published by Damuth (1987), Tucker et al. (2014), Tamburello et al. (2015), Nasrinpour et al. (2017), and Santini et al. (2018).

The annual rate of survival is one of the more difficult traits to estimate. This is reflected in the abovementioned datasets, where the maximum recorded lifespan tends to be the only survival related parameter. Yet, McCarthy et al. (2008) compiled more than 300 literature estimates for adult survival in mammals and birds. The Motoring Avian Productivity and Survivorship Program provides adult survival estimates for more than 190 North American bird species (DeSante and Kaschube 2009), and Ricklefs et al. (2011) used the age composition of museum collections to estimate about 90 survival rates for birds.

To extrapolate life history models across species, I combine the diverse data into a single dataset, and use standard calculations to transform some of the data into common parameters. The data are then checked for outliers and combined with allometric calculations to estimate the missing values of life history traits for all species with a data based estimate of body mass. This generates life history models for $89.4 \%$ of the bird species in Gill and Donsker (2014), and $89.1 \%$ of the mammals in Wilson and Reeder (2005).

\section{Methods}

The description of population dynamic feedback selection from the energy flow and density-dependent interactive competition in populations is published elsewhere (Witting 1997, 2008, 2017a,b). I restrict myself to the estimation of the underlying population level parameters for the different species, including the average life histories across the individuals of a population. Essential relations between the different traits are described in the appendix, with the overall model divided into the four components of individual growth, demographic traits, life history energetics, and population ecology.

\section{$2.1 \quad$ Individual growth}

The growth of an individual with age is described by

$t_{p}:$ the pregnancy period in mammals, and incubation period in birds; $t_{0}$ : the age at birth in mammals, and the age at hatching in birds, $t_{0}=0$;

$t_{j}$ : the age at weaning in mammals, and the age at fledging in birds;

$t_{i}$ : the age of independence from parents, $t_{j} \leq t_{i}<t_{m}$; $w$ : the average body mass of an adult individual;

$w_{x}$ : the mass at $t_{x}=t_{0}, t_{j}$ or $t_{i}$, with relative mass $\dot{w}_{x}=w_{x} / w$.

The growth of an individual - as measured by relative mass $\left(\dot{w}_{a}=w_{a} / w\right)$ over age $(a)$-is estimated by a Gompertz (1832) growth model

$$
\dot{w}_{a}=\dot{w} e^{-\gamma_{b} e^{-\gamma_{a}\left(a-t_{p}\right)}}
$$

where $w^{\prime}=w_{j} / \min \left(w_{j}, 0.95\right)$ to account for cases where the mass at weaning/fledging is larger than adult mass. The parameters of the growth model $\left(\gamma_{a}\right.$ and $\left.\gamma_{b}\right)$ are estimated by the growth curve that passes through $w_{0}$ at $a=t_{0}$, and $w_{j}$ at $a=t_{j}$. Assuming that parents invest at least $80 \%$ in the mass of offspring, the relative mass at independence is estimated as $\dot{w}_{i}=\max \left(w_{j}, 0.8\right)$, with $t_{i}$ being the solution to the growth curve at $\dot{w}_{i}=\dot{w} e^{-\gamma_{b} e^{-\gamma_{a}\left(t_{i}-t_{p}\right)}}$.

\subsection{Demography}

The demographic traits include

$t_{s}$ : female age of sexual maturity;

$t_{m}$ : female age of reproductive maturity, $t_{m}=t_{s}+t_{p}$;

$t_{r}$ : the expected reproductive period for females that survive to $t_{m}$, i.e., $t_{r}=1 /\left(1-p_{a d}\right)$ by eqn 12 ;

$t_{g}$ : generation time as the average age of reproduction, $t_{g}=t_{m}+p_{a d} /\left(1-p_{a d}\right)$ by eqn 15 ;

$t_{l}$ : the maximum lifespan of an individual;

$l_{m}$ : the probability that a new-born will survive to $t_{m}$, i.e., $l_{m}=2 / R$ by eqn 2 ;

$p_{a d}:$ the average annual survival probability of adults;

$q_{a d}:$ the average annual mortality of adults, $q_{a d}=1-$ $p_{a d} ;$

$l_{r}$ : the probability that an adult will survive the expected reproductive period, $l_{r}=p_{a d} t_{r}$; 


\begin{tabular}{l|rrrrrrrrrrrrrrrrr} 
& $w$ & $w_{0}$ & $w_{j}$ & $\beta$ & $\underline{\beta}$ & $t_{p}$ & $t_{j}$ & $t_{s}$ & $t_{m}$ & $t_{l}$ & $m_{b}$ & $m_{f}$ & $m_{i}$ & $p_{a d}$ & $N$ & $h$ \\
\hline Aves & 9488 & 778 & 207 & 76 & 356 & 2238 & 1822 & 1211 & 681 & 1674 & 7045 & 1772 & 0 & 869 & 1277 & 221 \\
Mammalia & 4865 & 1869 & 1058 & 57 & 708 & 2219 & 2042 & 1999 & 931 & 2617 & 3512 & 2147 & 651 & 276 & 1107 & 441 \\
\hline
\end{tabular}

\begin{tabular}{|c|c|c|c|c|c|c|c|c|c|c|c|c|c|c|c|c|c|}
\hline & $w$ & $\dot{w}_{0}$ & $\dot{w}_{j}$ & $\beta$ & $t_{x}$ & $m$ & $R$ & $l_{m}$ & $l_{r}$ & $\epsilon$ & $\alpha$ & $N$ & $b$ & $\epsilon_{n}$ & $h$ & $h_{o}$ & $I$ \\
\hline Exp. & 1 & 0 & 0 & $-\frac{1}{2 d}$ & $\frac{1}{2 d}$ & $-\frac{1}{2 d}$ & 0 & 0 & 0 & $\frac{2 d-1}{2 d}$ & 1 & $\frac{1-2 d}{2 d}$ & $\frac{1}{2 d}$ & 0 & 1 & $\frac{1}{2 d}$ & 0 \\
\hline
\end{tabular}

Table 1: Top table: The number of available data estimates per trait for birds and mammals. Bottom table: The theoretical exponents of body mass allometries from Witting $(1995,2017 \mathrm{a})$, with $t_{x} \in\left\{t_{p}, t_{j}, t_{s}, t_{m}, t_{r}, t_{g}, t_{l}\right\}$. The spatial dimensionality $(d)$ of the foraging behaviour is listed in Table 2 .

\begin{tabular}{rrrr} 
Class & Order & Family & $d$ \\
\hline Aves & - & - & 2 \\
Mammalia & - & - & 2 \\
Mammalia & Primates & - & 3 \\
Mammalia & Carnivora & - & 2 \\
Mammalia & Carnivora & Otariidae & 3 \\
Mammalia & Carnivora & Odobenidae & 3 \\
Mammalia & Carnivora & Phocidae & 3 \\
Mammalia & Cetacea & - & 3 \\
\hline
\end{tabular}

Table 2: The spatial dimensionality (d) of the foraging behaviour is set to depend on taxonomic level, following the classification in Witting (2017a).

$m$ : the average number of offspring produced per female per year, i.e., $m=m_{b} m_{f}$ where $m_{b}$ is the average brood size and $m_{f}$ the average brood frequency, with $m_{f}$ being the inverse $m_{f}=1 / m_{i}$ of the average brood interval $m_{i}$; and

$R$ : the average number of offspring produced over the expected reproductive period for females that survive to $t_{m}$, i.e., $R=t_{r} m$.

These parameters are estimated for stable populations with a per-generation growth rate of unity

$$
\lambda=l_{m} t_{r} m / 2=1
$$

\subsection{Life history energetics}

Traits that link the demographic parameters to the energetics of the organism include

$\underline{\beta}$ : basal mass-specific metabolism (SI unit $\mathrm{W} / \mathrm{g}$ );

$\beta$ : field mass-specific metabolism (SI unit $\mathrm{W} / \mathrm{g}$ );

$\tilde{\beta}$ : metabolic pace (SI unit $\mathrm{Hz}$ ), defined as $\tilde{\beta}=\beta / W$, i.e., the frequency of the metabolic work $W=1 \mathrm{~J} / \mathrm{g}$ that is carried out when one joule is metabolized per gram of tissue; $\alpha$ : the handling of net resource assimilation (resource handling in short, SI unit J), defined as the net energy that is generated per metabolic pace, and estimated as $\alpha=\epsilon / \tilde{\beta}$. Handling is a joint parameter $(\alpha=\grave{\alpha} \rho)$ of intrinsic handling $(\grave{\alpha})$ multiplied by the density of the resource $(\rho)$;

$\epsilon$ : the net assimilated energy that is available for reproduction is parameterised as a product $\epsilon=\alpha \tilde{\beta}$ (SI unit $\mathrm{W}$ ) between the handling of the resource $(\alpha)$ and the pace of handling $(\tilde{\beta})$. It is estimated as $\epsilon=w_{e} \hat{\beta} R / t_{r}$ from eqn 3 ;

$\epsilon_{g}:$ relative to net energy, the gross assimilated energy includes also energy used for metabolism, growth, and self-maintenance. It is estimated as $\epsilon_{g}=\epsilon / 2+$ $w \beta$ from eqn 23 (SI unit $\mathrm{W}$ ), and presented as a relative measure $\dot{\epsilon}_{g}=\epsilon_{g} / \epsilon$ of gross over net energy; and

$w_{\epsilon}$ : body mass measured by combustion energy (SI unit $\mathrm{J})$; calculated as $w_{\epsilon}=c_{w \rightarrow d} c_{d \rightarrow \epsilon} w$ where $w$ is mass in grams, $c_{w \rightarrow d}$ is the conversion of wet to dry organic matter [set to 0.40 for birds (Mahoney and Jehl 1984), and 0.35 for mammals (Prothero $2015)]$, and $c_{d \rightarrow \epsilon}$ is the conversion of dry organic matter to energy [set to $22.6 \mathrm{~kJ} / \mathrm{g}$ based on Odum et al. (1965) and Griffiths (1977)].

Net energy defines lifetime reproduction by the number of fully growth offspring that it produces. Assuming complete parental investment until $t_{i}$, we have

$$
R=\epsilon t_{r} / \dot{\beta} w_{\epsilon}
$$

where

$$
\dot{\beta}=\left(w_{i}+t_{e} \beta \bar{w}_{i}\right) / w
$$

is a scaling parameter that scales $w_{\epsilon}$ to the mass at independence $\left(w_{i}\right)$ and accounts for the energy that is metabolised by the offspring during the period of parental care $\left(t_{e}=t_{p}+t_{i}\right)$, with $t_{e} \beta \bar{w}_{i}$ being the energy 
that is metabolised by the offspring during $t_{e}$, assuming constant mass-specific metabolism $(\beta)$ and an average size

$$
\bar{w}_{i}=\frac{1}{t_{e}} \int_{a=-t_{p}}^{t_{i}} w_{a} d a
$$

that is calculated by the growth model of eqn 1 , with $-t_{p}$ being the negative age at fertilisation.

\subsection{Population ecology}

Important population ecological components include

$N$ : population density (abundance), as the number of animals per $\mathrm{km}^{2}$;

$b$ : the standing biomass of the population, as $b=w N$ in $\mathrm{kg} / \mathrm{km}^{2}$;

$\epsilon_{n}$ : the energy consumption of the population, calculated as $\epsilon_{n}=\epsilon_{g} N\left(\right.$ in $\left.\mathrm{W} / \mathrm{km}^{2}\right)$;

$h$ : the average home range of an individual (in $\mathrm{km}^{2}$ );

$h_{o}$ : the average overlap of home ranges, calculated as the average home range divided by the average availability of space $(1 / N)$, i.e., $h_{o}=h N$. This ratio is also known as the sociality index of Armitage (1981); and

$v$ : the frequency of competitive encounters per individual per unit home range overlap, given only as a relative measure that is estimated as $v \propto v_{f} / l_{f}$, where $l_{f} \propto h^{1 / d}$ is the length of foraging tracks (assumed proportional to the $d$ th root of the $d$-dimensional home range) and $v_{f} \propto \beta_{\beta} w^{1 / 2 d}$ is the average speed of foraging on those tracks, as expected from allometric correlations with $\beta_{\beta}$ being the intercept of the metabolic allometry $\beta=\beta_{\beta} w^{-1 / 2 d}$ (Witting 1995, 2017a); and

$I$ : intra-specific interference competition per individual approximated as a relative measure $I \propto h_{o} v \propto$ $N h v$ that is obtained by multiplying the home range overlap with the frequency of competitive encounters per individual per unit home range overlap (Witting 1995, 2017a). All estimates of $I$ are rescaled to obtain a $\log$ value $(\iota=\ln I)$ of unity for the median across all species of birds.

\subsection{Data}

I use published data to estimate the life history models for all bird and mammal species with body mass estimates. All trait estimates that I obtained from the literature are treated as raw data, and my broader definition of data include also the traits of a species that are calculated from the raw data of that species.

Taxonomies and names were obtained from Wilson and Reeder (2005) for mammals and from Gill and Donsker (2014) for birds, and body masses were obtained primarily from Smith et al. (2004) for mammals and Dunning (2007) for birds. Primary data on basal metabolism were obtained from McNab (2008) for mammals and McKechnie and Wolf (2004) for birds, with field metabolic rates from Hudson et al. (2013). Data for parameters on reproduction, time periods, and individual growth were obtained from a variety of sources including Jetz et al. (2008), De Magalhães and Costa (2009), Jones et al. (2009), and Myhrvold et al. (2015). I conducted an independent literature search for annual survival rates across all major taxa of birds and mammals, with major data sources including McCarthy et al. (2008), DeSante and Kaschube (2009), Ricklefs et al. (2011), del Hoyo et al. (1992-2011), and Wilson and Mittermeier (2009-2014). Population densities were obtained from Damuth (1987) and Santini et al. (2018), and home range areas from Tucker et al. (2014), Tamburello et al. (2015), and Nasrinpour et al. (2017) with a separate literature search for bats and marine mammals.

Some of the data in these publications are the same. I determined the value of a trait for a species as the average of the available raw data, resulting in more weight to commonly agreed estimates. Table 1 list the number of species with raw data for different traits. Data were distributed relatively evenly across the taxonomic groups that are considered separately in this paper. For the traits in Table 1, there were on average raw data for $17 \%$ of the bird species and $30 \%$ of the mammalian species, with the latter including $32 \%$ for placentals, $41 \%$ for marsupials, and $21 \%$ for bats. These data, except for body mass estimates, were checked for outliers (see outlier SI), with a total of 222 outliers removed.

I list the literature references for all raw data (in SI on data references), and for the underlying raw data when derived traits are calculated from one or two underlying traits with raw data estimates. Higher-level data that are calculated from more traits are listed as data but with no specific reference. Traits that could not be calculated from the raw data of a species had missing values that were estimated by inter-specific extrapolations. 


\subsection{Estimating missing values}

I estimated missing values by the use of inter-specific body mass allometries and invariances following the allometric model of Witting (2017a).

Estimation level: Missing values were estimated at different taxonomic levels dependent upon the available data. The precision of an allometric estimate will generally increase with the number of data and decline with taxonomic level from genus over family and order to class. With the number of data points for any trait increasing with taxonomic level, we expect a trade-off where an estimator based on few data at a low taxonomic level will, at some point, provide a better estimate than an estimator with many data at a higher taxonomic level.

To determine the data limits - where lower-level estimators are preferred over a higher-level estimators with more data - I constructed a hierarchical estimator that used the lowest taxonomic level with a given number $\left(n_{d}\right)$ of data points. This number was estimated by a numerical minimization of the sum of squares of the difference between raw data and their predicted values, with the predicted data values of a species being predicted from the raw data of all other species.

Given the optimal missing value estimation of eqns 6 to 8 below, the minimization of the sum of squares between the raw data and their predicted values determined that the more precise estimates of missing values were obtained with a $n_{d}$ parameter around unity. Taxonomic proximity was thus prioritized over sample size, with missing values being calculated at the lowest taxonomic level with one or more raw data of the required parameters. Genus $(g)$ was prioritized over family $(f)$, family over order $(o)$, and order over class $(c)$.

Estimator optimisation: A missing parameter value for a mass invariant parameters - like $\dot{w}_{0}, \dot{w}_{j}$, and $l_{r}$ - was estimated as the average of the raw data across the lowest taxonomic level with raw data for that parameter. For mass-dependent parameters - like $t_{m}, t_{l}$, and $\beta$ - the missing values were calculated as allometric functions of mass. The age of reproductive maturity, e.g., was calculated as

$$
t_{m}(x, n)=t_{m, \circ} w^{\hat{t}_{m}}
$$

with $x$ denoting the lowest taxonomic level with raw data, and $n$ the number of data points at that level. The allometric exponent $\left(\hat{t}_{m}\right)$ and intercept $\left(t_{m, o}\right)$ were estimated as a joint function

$$
\hat{t}_{m}=q \hat{t}_{m, D}+(1-q) q_{x} \hat{t}_{m, T}
$$

$$
t_{m, \circ}=q t_{m, \circ, D}+(1-q) t_{m, \circ, T}
$$

of the theoretical expectations from Witting (1995, 2017a) [subscript $T$; e.g. $\hat{t}_{m, T}=1 / 2 d$ from Table 1 with ecological dimensionality $(d)$ from Table 2] and the $n$ data points at the $x$ th taxonomic level [subscript $D$, with $\hat{t}_{m, D}$ and $t_{m, \circ, D}$ being point estimates from a linear regression on double logarithmic scale]. The weight

$$
q=1-e^{-e^{-q_{g}\left(n-q_{n}\right)}}
$$

of the data estimate increases monotonically from zero to one as a function of $n$, except for $n \leq 3$ cases where the exponent $\left(\hat{t}_{m}=q_{x} \hat{t}_{m, T}\right)$ was proportional to the theoretical expectation and the $t_{m, \circ}$ intercept of eqn 6 was the average allometric intercept for the $n$ species given the $\hat{t}_{m}$ exponent.

The three parameters $q_{g}, q_{n}$, and $q_{x}$ were estimated separately for all allometrically dependent life history parameters. This was done by a numerical minimization of the sum of squares (across species with data) for the difference between the raw data and the predicted values by the estimators at the lowest taxonomic levels, given the data of all the other species.

\subsection{Estimation sequence}

To estimate life history traits for all species with body mass estimates, I used a sequence of calculation where data and missing parameter estimates are constrained by the underlying demography, growth and energetic. This estimation includes four filters (see filter SI) that use model constraints and data distributions to adjust unexpected estimates in relation to lifespan, adult survival, gross energy, and the growth rated parameters $\dot{w}_{0}, \dot{w}_{j}$ and $t_{j}$.

I converted data on brood size $\left(m_{b}\right)$, brood frequency $\left(m_{f}\right)$ and/or brood interval $\left(m_{i}\right)$ to yearly reproduction $\left(m=m_{b} m_{f}, m_{f}=1 / m_{i}\right)$; and data on sexual maturity $\left(t_{s}\right)$ to reproductive maturity $\left(t_{m}=t_{s}+t_{p}\right)$. Data on total metabolism $(\beta w)$ were transformed to metabolic rates per unit mass $(\beta)$, and the ratio $(\beta / \underline{\beta})$ of field $(\beta)$ over basal $(\beta)$ metabolism was calculated for all species with data on both. Mortality $\left(q_{a d}=1-p_{a d}\right)$ data were calculated from survival rates $\left(p_{a d}\right)$ to have two mirror estimates of all survival data.

Missing values were then estimated for $m, t_{p}, t_{j}, t_{m}$, $t_{l}, w_{0}, w_{j}, h, N, \underline{\beta}, \beta / \underline{\beta}, p_{a d}$ and $q_{a d}$. Missing values for field metabolism $(\beta)$ were obtained from the $\beta / \beta$-ratio and basal metabolism. Missing values for $p_{a d}$ and $q_{a d}$ were first estimated independently by allometric correlations on $p_{a d}$ and $q_{a d}$, and adjusted afterwards to 


\begin{tabular}{|c|c|c|c|c|c|c|c|c|c|c|c|}
\hline & $\beta$ & $\underline{\beta}$ & $t_{m}$ & $t_{l}$ & $t_{i}$ & $t_{j}$ & $m$ & $p_{a d}$ & $q_{a d}$ & $N$ & $h$ \\
\hline$\overline{q_{g}}$ & 2.60 & 3.46 & 3.19 & 0.05 & 1.12 & 0.23 & 2.60 & 0.05 & 0.52 & 0.88 & 0.21 \\
\hline$q_{n}$ & 77.3 & 12.3 & 20.6 & 100.0 & 38.8 & 35.8 & 25.3 & 70.6 & 17.5 & 37.6 & 25.3 \\
\hline$q_{x}$ & 1.00 & 1.05 & 0.48 & 0.70 & 0.33 & 0.54 & 0.33 & 0.46 & 1.00 & 0.48 & 0.84 \\
\hline $\bar{x}$ & -0.25 & -0.24 & 0.01 & 0.14 & 0.04 & 0.14 & 0.00 & -0.11 & 0.08 & -0.31 & 1.02 \\
\hline$\sigma$ & 0.34 & 0.34 & 1.07 & 1.46 & 0.40 & 0.69 & 0.95 & 0.75 & 0.89 & 4.25 & 3.19 \\
\hline$\hat{x}$ & -0.27 & -0.28 & 0.13 & 0.13 & 0.08 & 0.15 & -0.09 & 0.11 & -0.18 & -0.35 & 0.72 \\
\hline$\sigma$ & 0.21 & 0.20 & 0.42 & 0.65 & 0.20 & 0.36 & 0.75 & 0.65 & 0.80 & 1.66 & 1.69 \\
\hline$\hat{x}$ & -0.26 & -0.27 & 0.23 & 0.21 & 0.13 & 0.20 & -0.16 & 0.11 & -0.23 & -0.35 & 0.97 \\
\hline$\sigma$ & 0.19 & 0.20 & 0.57 & 0.50 & 0.11 & 0.19 & 0.79 & 0.08 & 0.22 & 0.56 & 0.89 \\
\hline$\hat{x}$ & -0.32 & -0.28 & 0.22 & 0.22 & 0.18 & 0.24 & -0.16 & 0.08 & -0.21 & -0.55 & 1.20 \\
\hline$\sigma$ & 0.03 & 0.03 & 0.01 & 0.00 & 0.00 & 0.03 & 0.03 & 0.00 & 0.00 & 0.18 & 0.05 \\
\hline$\overline{\mathrm{cV}}$ & 0.13 & 0.11 & 0.13 & 0.23 & 0.05 & 0.10 & 0.13 & 0.11 & 0.20 & 0.85 & $\overline{1.14}$ \\
\hline $\mathrm{n}$ & 634 & 585 & 2480 & 3557 & 3698 & 3179 & 3138 & 660 & 660 & 1653 & 343 \\
\hline $\mathrm{cv}$ & 0.14 & 0.14 & 0.21 & 0.28 & 0.10 & 0.18 & 0.23 & 0.16 & 0.23 & 0.97 & 1.10 \\
\hline $\mathrm{n}$ & 415 & 405 & 486 & 591 & 675 & 595 & 596 & 338 & 338 & 609 & 254 \\
\hline $\mathrm{cv}$ & 0.23 & 0.20 & 0.23 & 0.26 & 0.19 & 0.28 & 0.28 & 0.18 & 0.35 & 1.44 & 1.56 \\
\hline $\mathrm{n}$ & 61 & 63 & 42 & 42 & 60 & 57 & 57 & 60 & 60 & 50 & 43 \\
\hline $\mathrm{cv}$ & 0.30 & 0.23 & 0.54 & 0.29 & 0.11 & 0.38 & 0.27 & 0.18 & 0.32 & 1.25 & 2.54 \\
\hline $\mathrm{n}$ & 10 & 10 & 6 & 6 & 4 & 3 & 2 & 9 & 9 & 14 & 10 \\
\hline
\end{tabular}

Table 3: Missing value estimation. The $q_{g}, q_{n}$ and $q_{x}$ parameters of eqns 7 and 8 that gave the most precise estimation of missing values for the different mass-dependent traits. $\hat{x}$ is the average, and $\sigma$ the standard deviation, of the data estimated allometric exponents at the different taxonomic levels (blue:genus; green:family; yellow:order; red:class). The precision of an estimated missing value is given by a coefficient of variation (cv) that is estimated from the missing value predictions of $\mathrm{n}$ data points.

identical mirror values in order to avoid unrealistic estimates where $p_{a d}>1 \wedge q_{a d}<0$ or $p_{a d}<0 \wedge q_{a d}>1$. With $p_{a d}^{-}$being the average survival rate for the two missing parameter estimates of $p_{a d}$ and $q_{a d}$, the adjustment was done by setting $q_{a d}=1-p_{a d}$ for $p_{a d}^{-} \leq 0.25$, by setting $p_{a d}=1-q_{a d}$ for $p_{a d}^{-} \geq 0.75$, and by setting $p_{a d}=p_{a d}^{-}$and $q_{a d}=1-p_{a d}^{-}$for $0.25<p_{a d}^{-}<0.75$.

A survival/mortality filter was constructed from an invariant $i_{m}=l_{m} / p_{a d}^{t_{m}}$-ratio. As adult survival is larger than offspring and juvenile survival in most species, we expect the $l_{m}$ ratio to be somewhat smaller than unity in nearly all species. From the $l_{m}$ distributions across all species, I determined an upper limit on $\hat{l}_{m}$ of 0.8 for birds and 0.95 mammals. Then, as $l_{m}=2 / t_{r} m=2\left(1-p_{a d}\right) / m$, we find that models with $\hat{l}_{m}$ ratios above these limits may have an estimate of the reproductive rate $(m)$ that is too low, or an estimate of the reproductive age $\left(t_{m}\right)$ that is too high, or an estimate of adult survival $\left(p_{a d}\right)$ that is too low.

For species that failed to pass the survival filter (i.e., $i_{m}>0.8$ for birds; $l_{m}>0.95$ for mammals), I would fist examine for the possibility of outlier data for $m$ and $t_{m}$. For this I would, for species with $m$ and/or $t_{m}$ data, estimate the corresponding missing parameter values for $m$ and $t_{m}$. If one of the latter two estimates made the species pass the survival filter, I would classify the data value as an outlier. If no outlier was identified I would increase adult survival to obtain a $\hat{l}_{m}$ ratio that resembled the missing parameter estimate of $l_{m}$ for that species. I would then remove the $p_{a d}$ and $q_{a d}$ outliers from the main data and rerun the complete estimation sequence until no extra outliers were identified.

Estimates for $t_{r}, t_{g}, R, l_{r}$, and $l_{m}$ were then calculated as $t_{r}=1 /\left(1-p_{a d}\right)$ by eqn $12, t_{g}=t_{m}+p_{a d} /(1-$ $\left.p_{a d}\right)$ by eqn $15, R=t_{r} m, l_{r}=p_{a d}^{t_{r}}$ by eqn 14 , and $l_{m}=2 / t_{r} m$ by eqn 2 .

A lifespan filter adjusted unlikely small $t_{l}$ values, and all growth related parameters $\dot{w}_{0}, \dot{w}_{j}$, and $t_{j}$ were filtered for unexpected values, where after the parameters of eqn 1 were calculated as $\gamma_{a}=\ln \left(\ln \left[\dot{w}_{0} / w^{\prime}\right] / \ln \left[\dot{w}_{j} / w^{\prime}\right]\right) /\left(t_{j}-t_{0}\right)$ and $\gamma_{b}=$ $-e^{c t_{j}} \ln \left(\dot{w}_{j} / \dot{w}\right) . \quad \bar{w}_{j}$ was then estimated by eqn 5 , net energy by eqn 20, gross energy by eqn 23 and the gross energy filter, resource handling as $\alpha=\epsilon / \beta$, home range overlap as $h_{o}=h N$, encounter rate as $v=$ $\beta w^{1 / 2 d} / h^{1 / d}$, and the level of interference as $I=h_{o} v$ followed by a rescaling to set $\iota=\ln I$ equal to unity for the median across all birds.

\section{Results}

\subsection{Estimator optimisation}

Given estimators at the lowest taxonomic level with data, the optimal values of the parameters for eqns 7 and 8 are listed in Table 3 . They follow a general pattern where missing parameters are calculated from the theoretical exponents for estimators with few available 



Figure 1: Data estimation. The estimation of missing parameters by allometric correlations was tested and optimised by the ability to predict the actual data; as illustrated here by the relationships between the data and their estimates on double logarithmic scale. Residuals are shown in insert plots, and the precision (cv) of the estimates are given in Table 3. Estimator levels: genus (blue), family (green), order (yellow), and class (red); with points of the latter sitting on top of the former.

data. With an increased number of data there is an often steep transition to a fully empirically based estimator, with the average values of the empirically estimated exponents listed in Table 3, for estimators at the genus (blue), family (green), order (yellow), and class (red) level.

The average precision (cv) of the missing parameter estimates are also listed in the table. Excluding the estimator for abundance $(N)$ and home range $(h)$, the precisions are generally acceptable for all estimators. The average $\mathrm{cv}$ is 0.23 , with a range that varies from 0.05 to 2.54. Precision is generally declining with an increase in the taxonomic level of the estimator, with the average $\mathrm{cv}$ being 0.21 at the genus level, 0.32 at the family level, 0.44 at the order level, and 0.72 at the class level.

The underlying relationships between the raw data and their values as predicted by the optimal estimators are show Fig. 1. There is a close to linear dependence for all traits, except that the maximum lifespan and survival estimators tend to overestimate for small body masses.

\subsection{Estimation levels}

The proportions of the parameters that are given by data and the different estimators are shown in Fig. 2. Mammals have a larger fraction of data than birds for most of the parameters, yet even in birds 85\%, 93\%, $92 \%, 89 \%, 74 \%$, and $87 \%$ of the estimates for $m, N$ (and $b), t_{p}, t_{j}, t_{m}$ and $t_{l}$ are at or below the family level. The corresponding values are 100\%, 88\%, 99\%, $99 \%, 98 \%$, and $95 \%$ for mammals, where $43 \%, 22 \%$, $45 \%, 41 \%, 37 \%$, and $45 \%$ of the estimates are data.

Other parameters with a relatively strong data basis include metabolism, where $4 \%$ and $15 \%$ of the estimates in birds and mammals are data, and $74 \%$ and $95 \%$ are at or below the family level. Adult survival and $t_{r}=1 /\left(1-p_{a d}\right)$ are also well supported, with $9 \%$ and $4 \%$ of the estimates in birds and mammals being data, and $89 \%$ and $79 \%$ being at or below the family level. The mass at birth $\left(\dot{w}_{0}\right)$ and weaning $\left(\dot{w}_{j}\right)$ is strongly supported by data in mammals ( $37 \%$ \& $22 \%$ are data), but less so in birds especially for mass at fledging $(8 \%$ $\& 2 \%$ are data). 

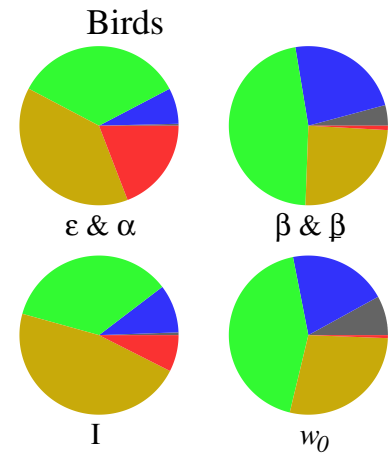

Mammals

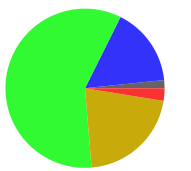

$\varepsilon \& \alpha$

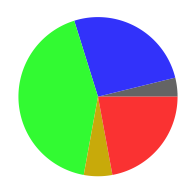

I

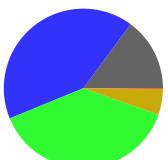

$\beta \& \beta$

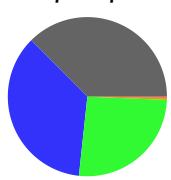

$w_{0}$

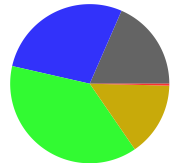

m

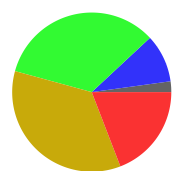

$w_{j}$

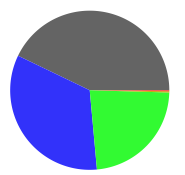

m



$w_{j}$

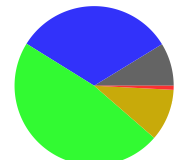

$p_{a d} \& t_{r}$

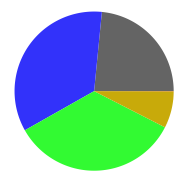

$t_{i}$
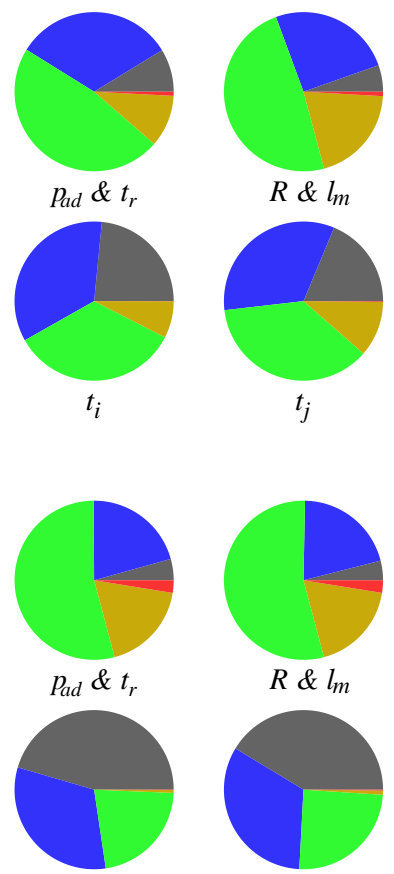

$t_{i}$
$R \& l_{m}$

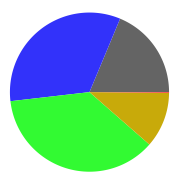

$t_{j}$

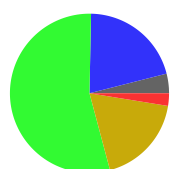

$R \& l_{m}$

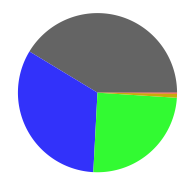

$t_{j}$

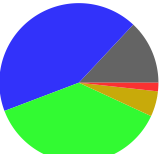

$N \& b$

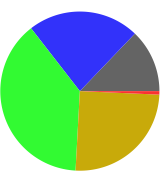

$t_{m}$

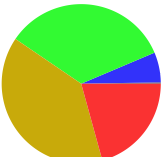

$\varepsilon_{n}$

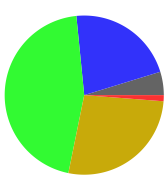

$t_{g}$

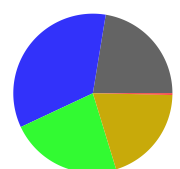

$N \& b$

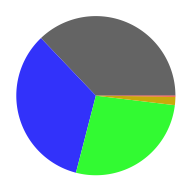

$t_{m}$



$\varepsilon_{n}$

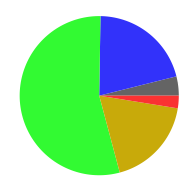

$t_{g}$

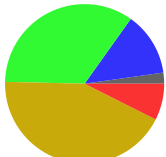

h
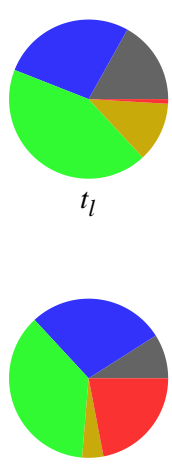

h

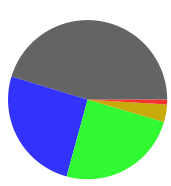

$t_{l}$

Figure 2: Estimator distributions for 9,488 species of birds, and 4,865 species of mammals. Estimator levels: data (black), genus (blue), family (green), order (yellow), and class (red).

The parameters that are less supported by data are typically calculated from at least two independent parameters, with estimator levels given by the parameter that is estimated at the highest taxonomic level. These parameters include $\epsilon, \alpha, R, l_{m}, \epsilon_{n}, I$, and $t_{g}$. Yet, even net energy $(\epsilon)$ and resource handling $(\alpha)$ - which are calculated from seven underlying parameters - have $42 \%$ and $76 \%$ of the estimates in birds and mammals at or below the family level.

\subsection{Estimation space}

The allometric relationships between selected parameters and body mass are shown in Fig. 3. The black lines in the plots connect data, forming trees that illustrate the parameter space of the data. The estimated parameters for individual species are plotted by dots, with the taxonomic level of the estimator indicated by colour. The coloured dots show that the extrapolation of parameters across species tends to be contained within the overall parameter space of the available data.

This is true especially for parameters with many data, where the black trees tend to cover almost the complete parameter space of the estimates. Yet, narrow extrapolation areas exists, like the line of order-level dots (yellow) for the allometric scaling of metabolism $(\beta)$ in larger mammals.

The parameters with fewer data have large data free areas that are dominated by especially order and family level estimators. Yet, these extrapolation areas tend to be contained within the space of widely scattered data. This illustrates that the estimated models are contained within the data supported life histories, instead of being extrapolated into areas that are not supported by data.

The general resemblance-between the estimated parameters and the underlying data distributionsprovide confidence in the extrapolation of life history models. The estimated models for ten randomly chosen species of mammals and birds are listed in Table 4 for the growth and demographic related parameters, and in Table 5 for the energetic and population ecology related parameters. The complete sets of models for 9,488 species of birds, and 4,865 species of mammals, are listed in the SI.

The growth and demographic models in Table 4 are estimated at different levels, including complete models that are estimated at the genus and family level, as well as models with parameter estimates at different levels. Across the complete set of growth models for birds and mammals, $68 \%$ and $46 \%$ are based on estimators at 


\begin{tabular}{|c|c|c|c|c|c|c|c|c|c|c|c|c|c|c|c|}
\hline Trait & $w$ & $w_{0}$ & $w_{j}$ & $t_{p}$ & $t_{j}$ & $\gamma_{a}$ & $\gamma_{b}$ & $t_{m}$ & $t_{r}$ & $t_{g}$ & $t_{l}$ & $l_{m}$ & $p_{a d}$ & $m$ & $R$ \\
\hline Unit & $\mathrm{kg}$ & - & - & $y$ & $y$ & - & - & $y$ & $y$ & $y$ & $y$ & $p$ & $p$ & $\frac{1}{y}$ & $\frac{1}{t_{r}}$ \\
\hline $\begin{array}{l}\text { Coppery Ringtail } \\
\text { Pseudochirops cupreus }\end{array}$ & $\begin{array}{c}a: c: d \\
1.8\end{array}$ & .00023 & .24 & .044 & .5 & 3.5 & 9.8 & 1.4 & 4.1 & 4.6 & 5.6 & .45 & .76 & 1.1 & 4.5 \\
\hline $\begin{array}{l}\text { San Quintin Kangaroo Rat } \\
\text { Dipodomys gravipes }\end{array}$ & $\begin{array}{l}a: c: d \\
.084\end{array}$ & .068 & .39 & .083 & .073 & 14 & 8.9 & .28 & 1.2 & .51 & 6.6 & .32 & .19 & 5.1 & 6.3 \\
\hline $\begin{array}{l}\text { Buff-bellied Rhipidomys } \\
\text { Rhipidomys ochrogaster }\end{array}$ & $\begin{array}{l}a: c: d \\
.089\end{array}$ & .071 & .36 & .074 & .062 & 15 & 8 & .25 & 1.5 & .71 & 4.6 & .1 & .32 & 13 & 19 \\
\hline $\begin{array}{l}\text { Chiapan Climbing Rat } \\
\text { Tylomys bullaris }\end{array}$ & $\begin{array}{c}a: c: d \\
.28\end{array}$ & .071 & .16 & .11 & .073 & 5 & 4.6 & .29 & 1.7 & .98 & 5.6 & .086 & .41 & 14 & 23 \\
\hline $\begin{array}{l}\text { Greater Forest Shrew } \\
\text { Sylvisorex ollula }\end{array}$ & $\begin{array}{l}a: c: d \\
.015\end{array}$ & .068 & .77 & .065 & .063 & 37 & 30 & .3 & 1.2 & .48 & 2.8 & .12 & .15 & 14 & 16 \\
\hline $\begin{array}{l}\text { Seychelles Flying Fox } \\
\text { Pteropus seychellensis }\end{array}$ & $\begin{array}{l}a: c: d \\
.48\end{array}$ & .14 & .51 & $\begin{array}{l}c: d \\
.43\end{array}$ & .37 & 2.9 & 6.9 & 1.6 & 6.8 & 7.4 & $\begin{array}{c}d \\
9.9\end{array}$ & .3 & .85 & $\begin{array}{c}c: d \\
1\end{array}$ & 6.8 \\
\hline $\begin{array}{l}\text { Hairy Little Fruit Bat } \\
\text { Rhinophylla alethina }\end{array}$ & $\begin{array}{c}d \\
.0069\end{array}$ & .16 & .65 & .32 & .12 & 12 & 100 & .82 & 3 & 2.8 & 10 & .66 & .67 & 1 & 3 \\
\hline $\begin{array}{l}\text { Thumbless Bat } \\
\text { Furipterus horrens }\end{array}$ & $\begin{array}{l}a: c: d \\
.0032\end{array}$ & .18 & .65 & .22 & .099 & 14 & 33 & .85 & 4.8 & 4.7 & 12 & .41 & .79 & 1 & 4.9 \\
\hline $\begin{array}{l}\text { Sechuran Fox } \\
\text { Lycalopex sechurae }\end{array}$ & $\begin{array}{c}a: c: d: e \\
4.1\end{array}$ & .02 & .17 & .15 & .18 & 4.4 & 7.6 & .86 & 2.5 & 2.3 & $\begin{array}{c}d \\
9.9\end{array}$ & .18 & .59 & 4.5 & 11 \\
\hline $\begin{array}{l}\text { Atlantic White-sided Dolphin } \\
\text { Lagenorhynchus acutus }\end{array}$ & $\begin{array}{c}a: c: d: e \\
190\end{array}$ & $\begin{array}{l}c: d \\
.13\end{array}$ & .34 & $\begin{array}{l}c: d \\
.87\end{array}$ & $\begin{array}{l}c: d \\
1.5\end{array}$ & .43 & 3 & $\begin{array}{l}e \\
6.1\end{array}$ & 25 & 30 & 31 & .16 & .96 & $\begin{array}{l}c: d: e \\
.5\end{array}$ & 12 \\
\hline $\begin{array}{l}\text { Shy Albatross } \\
\text { Thalassarche cauta }\end{array}$ & $\begin{array}{c}b: d \\
4\end{array}$ & .047 & 1.1 & $\begin{array}{c}d \\
.19 \\
\end{array}$ & $\begin{array}{l}d \\
.4 \\
\end{array}$ & 10 & 23 & 10 & 14 & 24 & $\begin{array}{c}d \\
40\end{array}$ & .28 & .93 & $\begin{array}{l}d \\
.5\end{array}$ & 7.2 \\
\hline $\begin{array}{l}\text { Barolo Shearwater } \\
\text { Puffinus baroli }\end{array}$ & $\begin{array}{c}d \\
.19\end{array}$ & .1 & 1.1 & $\begin{array}{c}d \\
.14 \\
\end{array}$ & $\begin{array}{l}d \\
.2 \\
\end{array}$ & 20 & 38 & 4.8 & 10 & 14 & $\begin{array}{c}d \\
19 \\
\end{array}$ & .19 & .9 & $\begin{array}{l}d \\
1 \\
\end{array}$ & 10 \\
\hline $\begin{array}{l}\text { Long-legged Buzzard } \\
\text { Buteo rufinus }\end{array}$ & $\begin{array}{c}b: d: e \\
1.2\end{array}$ & .042 & .99 & $\begin{array}{c}d \\
.09\end{array}$ & $\begin{array}{c}d \\
.13\end{array}$ & 32 & 61 & $\begin{array}{l}d \\
2\end{array}$ & 5.9 & 6.9 & $\stackrel{d}{8.5}$ & .11 & .83 & $\begin{array}{l}d: i \\
3\end{array}$ & 18 \\
\hline $\begin{array}{l}\text { Arabian Scops Owl } \\
\text { Otus pamelae }\end{array}$ & $\begin{array}{c}d \\
.069\end{array}$ & .098 & .93 & .067 & .068 & 52 & 74 & .96 & 3.6 & 3.5 & 9.5 & .15 & .72 & 3.7 & 13 \\
\hline $\begin{array}{l}\text { Social Flycatcher } \\
\text { Myiozetetes similis }\end{array}$ & $\begin{array}{l}b: d \\
.028\end{array}$ & .11 & .91 & $\begin{array}{c}d \\
.042\end{array}$ & $\begin{array}{c}d \\
.058\end{array}$ & 56 & 24 & 1 & 2.4 & 2.4 & 9 & .14 & .58 & 6 & 14 \\
\hline $\begin{array}{l}\text { Orange-crowned Fairywren } \\
\text { Clytomyias insignis }\end{array}$ & $\begin{array}{l}b: d \\
.012 \\
\end{array}$ & .082 & .81 & .037 & .035 & 69 & 32 & 1 & 2.8 & 2.8 & 11 & .12 & .64 & 6 & 17 \\
\hline $\begin{array}{l}\text { Yellow-throated Greenbul } \\
\text { Arizelocichla chlorigula }\end{array}$ & $\begin{array}{c}d \\
.035 \\
\end{array}$ & .072 & .81 & .036 & .036 & 69 & 30 & 1.1 & 2.3 & 2.4 & 10 & .14 & .56 & 6.3 & 14 \\
\hline $\begin{array}{l}\text { Goulds Shortwing } \\
\text { Heteroxenicus stellatus }\end{array}$ & $\begin{array}{c}b: d \\
.023 \\
\end{array}$ & .099 & 1.1 & .038 & .04 & 96 & 93 & 1 & 2 & 2 & 8.9 & .14 & .5 & 7.2 & 14 \\
\hline $\begin{array}{l}\text { Altai Accentor } \\
\text { Prunella himalayana }\end{array}$ & $\begin{array}{l}b: d \\
.027\end{array}$ & .082 & .81 & .035 & .036 & 69 & 28 & 1 & 3.4 & 3.4 & 13 & .068 & .7 & 8.8 & 30 \\
\hline $\begin{array}{l}\text { Stripe-tailed Yellow Finch } \\
\text { Sicalis citrina }\end{array}$ & $\begin{array}{l}b: d \\
.012\end{array}$ & .097 & .81 & .034 & .035 & 68 & 24 & .91 & 2.6 & 2.5 & 9.4 & .17 & .61 & 4.7 & 12 \\
\hline
\end{tabular}

Table 4: Growth and demography for ten randomly chosen mammal and bird species. Estimator levels: data (black), genus (blue), family (green), order (yellow), and class (red). The superscript letters for data refer to references in the SI on data references.

different taxonomic levels. The growth estimates for mammals have a fair share of pure data (17\%), genus $(18 \%)$ and family $(17 \%)$ level models, while these are less common in birds with corresponding proportions of $1.3 \%, 5.8 \%$, and $14 \%$. For the demographic traits, $57 \%$ and $78 \%$ of the models for birds and mammals include estimators at different taxonomic levels. Mammals have some pure data $(3.7 \%)$, genus $(6.6 \%)$ and family $(11 \%)$ level models, and only $0.16 \%$ at the order level. Birds have a similar fraction of data models $(4.5 \%)$, and more at the genus $(13 \%)$, family $(22 \%)$, and order $(4 \%)$ level. With estimation at the class level having least precision, it is encouraging that only $0.1 \%$ of the growth, and $0.098 \%$ of the demographic, models are pure class-level models for birds and mammals combined.

The energetic and population ecology models in Table 5 are estimated at slightly higer taxonomic levels. Across the complete set of energetic models for birds and mammals, $45 \%$ and $48 \%$ include estimators at different taxonomic levels. The energetic estimates for mammals have few (1.5\%) pure data models, many $(32 \%)$ at the family level, and fewer at the genus (14\%) and order $(5.2 \%)$ level. Birds have even fewer data $(0.34 \%)$ and genus $(6.3 \%)$ models, and large fractions of family $(26 \%)$ and order $(21 \%)$ level models.

For the population ecological traits, the majority of models for birds (78\%) and mammals (58\%) include estimators at different taxonomic levels. Mammals have only $0.95 \%$ pure data models, and $8 \%$ genus, $22 \%$ fam- 
ily, and $11 \%$ order models. Birds have an even lower fraction $(0.15 \%)$ of data models, and $3.2 \%$ genus, $13 \%$ family, and $4.1 \%$ order models. Still, only $0.64 \%$ of the energetic, and $1.2 \%$ of the population ecological, models are pure class-level models for the two taxa combined.

\section{Conclusion}

The estimated species models reconcile 56,214 published data estimates on life history and ecological traits with the underlying inter-specific allometries of the data. All of the 14,353 species models are in an energetic balance that reconciles the resource assimilation, physiological growth, metabolism, and demographic traits of an average individual with the foraging ecology at the evolutionarily determined population dynamic equilibrium, where the natural selection of the interactive competition in the overlapping areas of individual home ranges determines the abundance, biomass, and energy consumption of populations.

With the majority of the estimated life history traits being inter-specific extrapolations, it is essential to use the estimated models with caution. Instead of treating them as final estimates, I recommend to use them as prior knowledge in the absence of data on particular species and populations. This can be as prior distributions in statistical analyses, for educational and illustrational purposes, or as first approximations for population viability analyses in data poor cases.

Examples on their use are presented in five papers, where Witting (2021a) uses the estimated life histories to illustrate natural selection causes for the evolution of the inter-specific body mass allometries, and Witting (2021b,d) uses population dynamic feedback selection to decompose the inter-specific variation in the life histories and population ecology of birds and mammals. The inter-specific distributions of the estimated parameters are presented by Witting (2021c) in a discussion on evolutionary differences in the ecology and life histories of birds and mammals, and Witting (2021e) uses a subset of the estimated equilibrium models as starting points for the development of selection-regulated population dynamic models that predict population dynamic trajectories for hundreds of species.

\section{Supplementary Information}

Not available in this pre-print, but all life history models are available at https://mrLife.org.

si_outlier.pdf: On the removal of outlier data; si_filter.pdf: On the four estimation filters;

si_bird_demo.pdf: Demographic estimates for birds;

si_mamm_demo.pdf: Demographic estimates for mammals;

si_bird_energy.pdf: Energetic \& ecological estimates for birds;

si_mamm_energy.pdf: Energetic \& ecological estimates for mammals;

si_ref.pdf: Data references;

\section{Acknowledgements}

I thank all that have collected and published life history data for birds and mammals.

\section{Appendix}

\section{A Demography}

I estimate the average demographic parameters for stable populations where the per-generation growth rate is unity

$$
\lambda=l_{m} R / 2=1
$$

with $l_{m}$ being the probability that a new born survives to the age of maturity $\left(t_{m}=t_{s}+t_{p}\right.$, first reproductive event with $t_{s}$ being age of sexual maturity and $t_{p}$ the incubation/pregnancy period), and $R$ is the expected lifetime reproduction of females that survives to $t_{m}$ assuming an even sex ratio.

As data on age $(a)$ structured reproduction is rarely available I estimate lifetime reproduction as a product

$$
R=t_{r} m
$$

where $t_{r}$ is the expected reproductive period for females that survives to $t_{m}$, and $m$ is the average number of offspring/births per female per year.

The average reproductive rate per year is calculated as a product

$$
m=m_{b} m_{f}
$$

between the average brood size $\left(m_{b}\right)$ and the average brood frequency $\left(m_{f}\right)$, with the latter being the inverse of the average brood interval $\left(m_{f}=1 / m_{i}\right)$. 
bioRxiv preprint doi: https://doi.org/10.1101/2021.11.27.470200; this version posted November 27, 2021. The copyright holder for this preprint (which was not certified by peer review) is the author/funder, who has granted bioRxiv a license to display the preprint in perpetuity. It is made available under aCC-BY-NC-ND 4.0 International license.
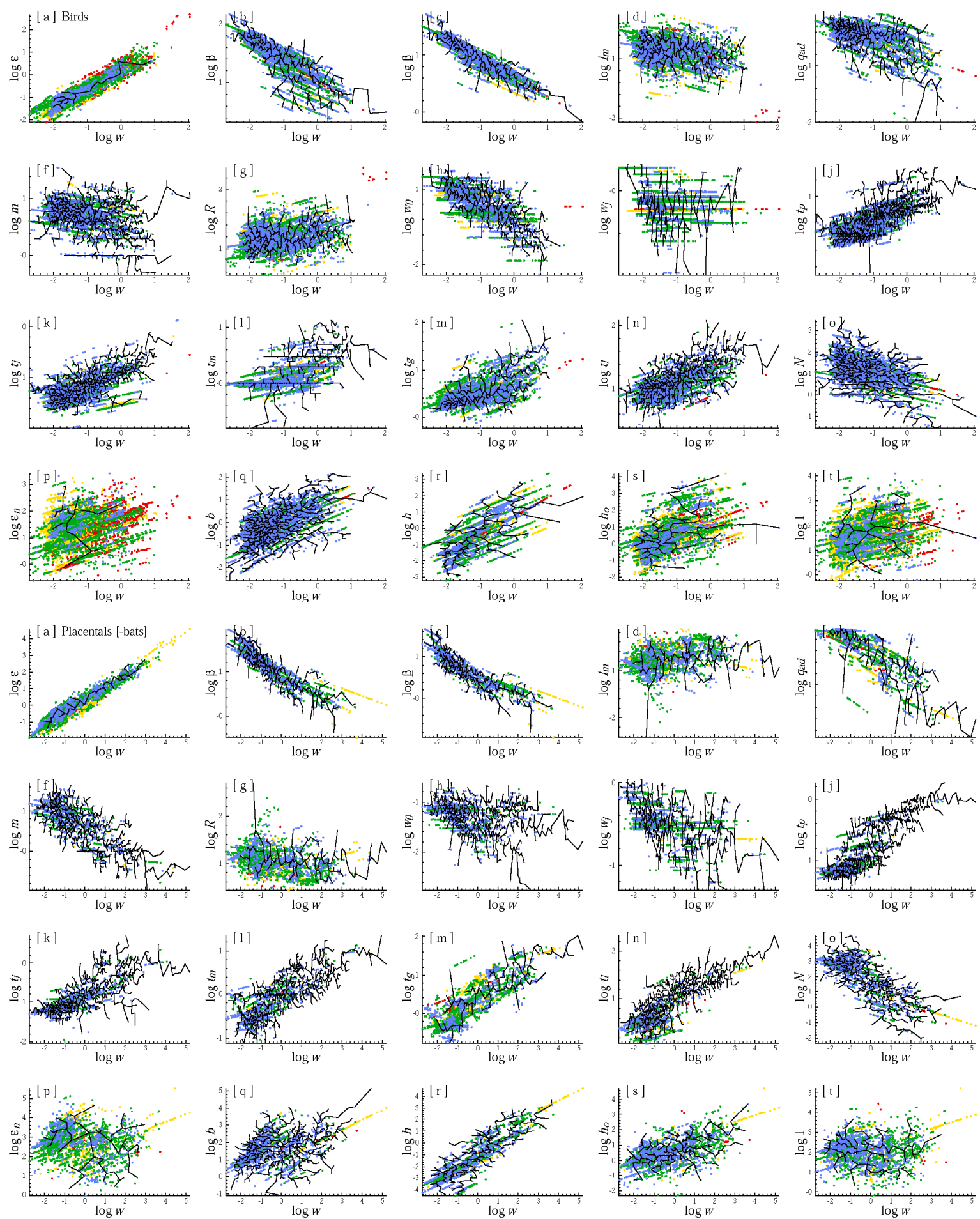

Figure 3: Allometric scaling. Birds in the top four rows, placental mammals in the bottom four. The black lines outline data, and the coloured dots estimates at different levels. Estimator levels: data (black), genus (blue), family (green), order (yellow), and class (red); with points of the latter sitting on top of the former. 


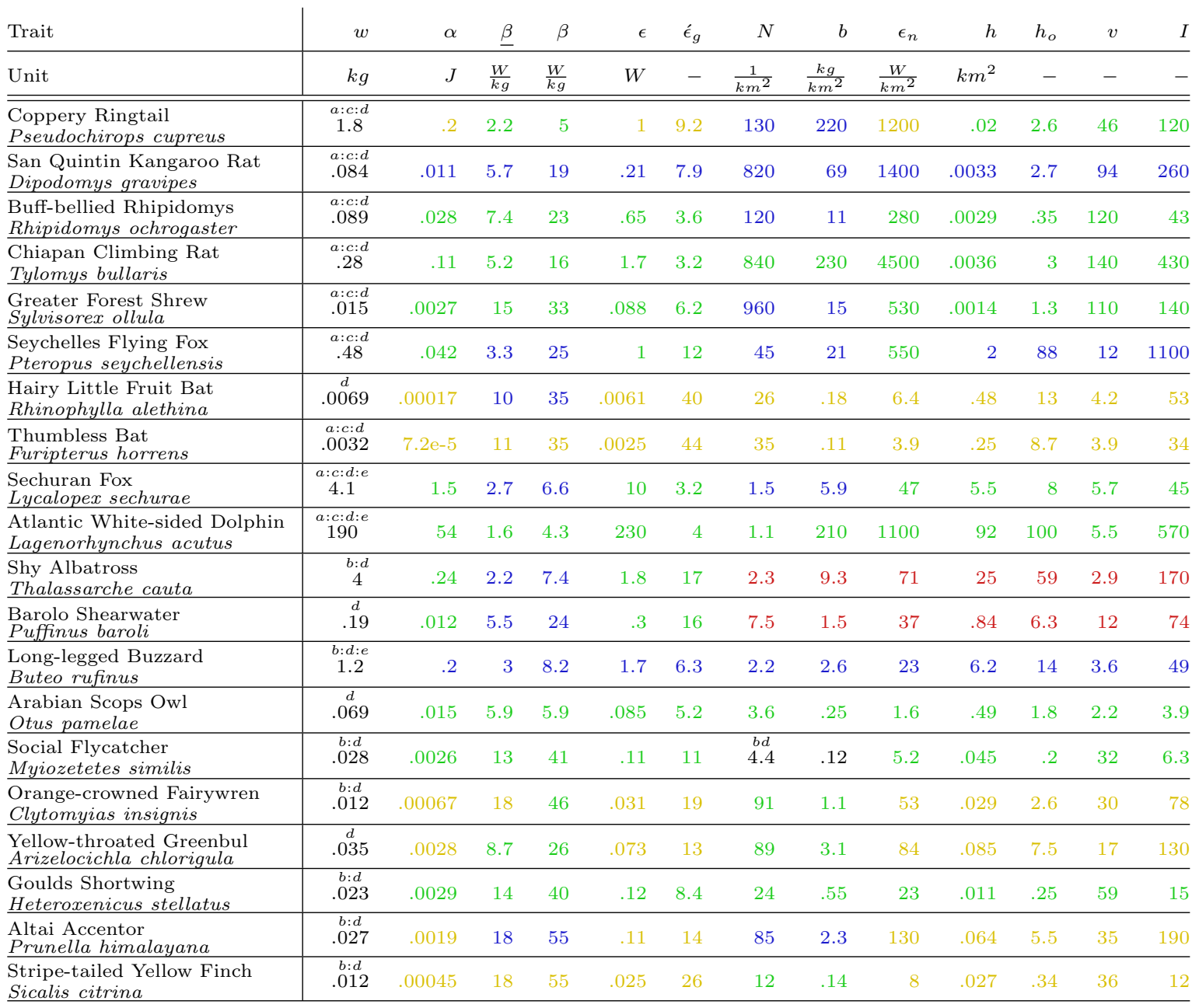

Table 5: Energetics and population ecology for ten randomly chosen mammal and bird species. Estimator levels: data (black), genus (blue), family (green), order (yellow), and class (red). The superscript letters for data refer to references in the SI on data references.

The expected reproductive period is calculated as a function of adult survival $\left(p_{a d}\right)$, where

$$
\begin{aligned}
t_{r} & =\frac{\sum_{a=t_{m}}^{t_{l}}\left(a+1-t_{m}\right)\left(l_{a}-l_{a+1}\right)}{\sum_{a=t_{m}}^{t_{l}} l_{a}-l_{a+1}} \\
& =\sum_{a=t_{m}}^{t_{l}} l_{a} / l_{m}=\sum_{a=t_{m}}^{t_{l}} p_{a d}^{a-t_{m}} \\
& \approx \sum_{i=0}^{\infty} p_{a d}^{i}=\frac{1}{1-p_{a d}}
\end{aligned}
$$

for a model with constant adult survival.

Estimates of adult survival were obtained either as direct estimates of $p_{a d}$, or calculated from cohort data $\left(n_{a}\right)$ or survival curves $\left(l_{a}\right)$, with $l_{a}=\prod_{x=0}^{a-1} p_{x}$ and $p_{x}$ being survival during age class $x$. These provide estimates of age-structured survival $\left(p_{a}=n_{a+1} / n_{a}=\right.$ $\left.l_{a+1} / l_{a}\right)$ so that average adult survival is estimated as

$$
p_{a d}=e^{\ln \left(\prod_{a=a_{b}}^{a_{x}} p_{a}\right) /\left(a_{x}-a_{b}+1\right)}
$$

where $a_{x}$ is the last age with a survival estimate $\left(p_{a_{x}}\right)$, and $a_{b}=\max \left(t_{m}, a_{f}\right)$ is the first age with a survival estimate for mature individuals, with $a_{f}$ being the first age with a survival estimate from the cohort data or survival curve.

Data on lifespan, age of maturity, brood size and brood interval is much more common than data on survival. When data on survival is available it will usually reflect only adult survival, or some fraction of the joint 
survival from new-born to the age of maturity. Complete data on age structured survival in natural populations is almost always missing. The probability to survive to the age of maturity is therefore estimated from eqn 9 as $l_{m}=2 / R$ given the assumption of a stable population. The probability that a new born will survive through the expected reproductive period is $l_{m} p_{a d}^{t_{r}}$, implying

$$
p_{a d}^{t_{r}}=l_{m} p_{a d}^{t_{r}} / l_{m}=l_{r}
$$

as an invariance for the likelihood that an adult will survive the expected reproductive period.

A scaling of the life history onto the timescale of population dynamics and natural selection requires information on generation time. A useful measure (Charlesworth 1980) is the mean age of reproduction

$$
t_{g}=\frac{\sum_{a=t_{m}}^{t_{l}} a m_{a} l_{a}}{\sum_{a=t_{m}}^{t_{l}} m_{a} l_{a}}
$$

With the survival curve $l_{a}$ missing in most cases, I assume constant yearly reproduction $(m)$ and constant adult survival $\left(p_{a d}\right)$, so that generation time reduces to a function of the age of maturity and adult survival

$$
\begin{aligned}
t_{g} & =\frac{m l_{m} \sum_{a=t_{m}}^{t_{l}} a p_{a d}^{a-t_{m}}}{m l_{m} \sum_{a=t_{m}}^{t_{l}} p_{a d}^{a-t_{m}}} \\
& =t_{m}+\frac{\sum_{a=t_{m}}^{t_{l}}\left(a-t_{m}\right) p_{a d}^{a-t_{m}}}{\sum_{a=t_{m}}^{t_{l}} p_{a d}^{a-t_{m}}} \\
& \approx t_{m}+\frac{\sum_{i=0}^{\infty} i p_{a d}^{i}}{\sum_{i=0}^{\infty} p_{a d}^{i}}=t_{m}+\frac{p_{a d}}{1-p_{a d}}
\end{aligned}
$$

\section{B Life history energetics}

To link the demographic parameters to the life history I use the energetic life history model of Witting (2017a), where the reproducing unit is selected by the population dynamic feedback selection of density-dependent competitive interactions. The reproducing unit that is selected by this mechanism may be a single asexual replicator, a sexually reproducing pair, a cooperatively reproducing family, or an eusocial colony (Witting 2002). High-energy organisms with evolutionarily flexible body masses - like mammals and birds - are predicted to have body masses that evolve as an allometric function of net energy $\left[w \propto \epsilon^{2 d /(2 d-1)}\right]$ and a sexual pair, or cooperative family, as the reproducing unit.

Following Witting $(2002,2017)$, the net energy $(\epsilon$, given in $\mathrm{J} / \mathrm{s}$ ) that the female has available for reproduction is

$$
\epsilon=\alpha \tilde{\beta}
$$

where $\tilde{\beta}=\beta / W$ is metabolic pace (in $1 / \mathrm{s}$ ), given as the frequency of the metabolic work $W=1 \mathrm{~J} / \mathrm{g}$ that is carried out when one joule is metabolized per gram of tissue, with $\beta$ (in $\mathrm{J} / \mathrm{sg}$ ) being the field mass-specific metabolism, and $\alpha$ (in $\mathrm{J}$ ) the resource handling, or net assimilated resource, per metabolic pace.

Assuming a sexual pair, the male is predicted to use the same amount of net energy in interactive competition. The gender-dependent use of net energy in reproduction or interactive competition will vary between natural species; yet the fraction of the total net energy $\left(\epsilon n_{r}\right)$ that is allocated to reproduction for a reproducing unit with $n_{r}$ individuals is predicted to be $\theta=1 / n_{r}$, i.e. 0.5 for sexually reproducing pairs (Witting 1997, 2002).

With $\epsilon$ being the average energy that is allocated to reproduction independently of the average size of the reproducing unit, the demographic parametersfor species with complete parental investment until the age of independence $\left(t_{i}\right)$ - are linked to net energy by the following quality-quantity trade-off

$$
R=\epsilon t_{r} / \dot{\beta} w_{\epsilon}
$$

where $w_{e}$ is adult mass in combustion energy, and

$$
\dot{\beta}=\left(w_{i}+t_{e} \beta \bar{w}_{i}\right) / w
$$

is a scaling parameter that scales $w_{\epsilon}$ to the mass of independence $\left(w_{i}\right)$ and accounts for the energy that is metabolised by the offspring during the period of parental care $\left(t_{e}=t_{p}+t_{i}\right)$, and $t_{e} \beta \bar{w}_{i}$ is the energy that is metabolised by the offspring during $t_{e}$, assuming constant mass-specific metabolism $(\beta)$ with the average mass of the offspring $\left(\bar{w}_{i}\right)$ being calculated by eqn 5 .

Given a stable population of sexually reproducing pairs, I combine $l_{m} R=2$, with eqns 18 and 19 to estimate net energy as

$$
\epsilon=\frac{2 w_{\epsilon}\left(w_{j}+t_{e} \beta \bar{w}_{j}\right)}{l_{m} t_{r} w}
$$

and resource handling as $\alpha=\epsilon W / \beta$.

Following Witting (2017a), the gross energy of a pure replicating individual - that does not participate in interactive competition and allocates all its net energy into replication - is net energy plus total metabolism. Yet, especially males use net energy in interactive competition, with the predicted fraction of the total net energy $\left(\epsilon n_{r}\right)$ that is used in interactive competition being $1-\theta$ for replicating units with $n_{r}$ individuals where $\theta=1 / n_{r}$.

Assuming that interactive energy is burned by extra metabolism, we find on average that the total metabolism of an organism

$$
w \beta=w \beta_{g}+w \beta_{n}
$$


contains a partial net component

$$
w \beta_{n}=(1-\theta) \epsilon
$$

that reflects the net energy that is burned in interactive competition, and a partial gross component $\beta_{g}$ that defines the difference between gross and net energy

$$
\begin{aligned}
\epsilon_{g} & =\epsilon+w \beta_{g}=\epsilon+w \beta-w \beta_{n} \\
& =\theta \epsilon+w \beta
\end{aligned}
$$

with $\theta=0.5$ for populations of sexually reproducing pairs.

\section{References}

Armitage K. B. (1981). Sociality as a life-history tactic of ground squirrels. Oecologia 48:36-49.

Bonner J. T. (1965). Size and cycle. Princeton University Press, Princeton.

Brown J. H., Hall C. A. S., Sibly R. M. (2018). Equal fitness paradigm explained by a trade-off between generation time and ennergy production rate. Nat. Ecol. Evol. 2:262-268.

Brown J. H., Marquet P. A., Taper M. L. (1993). Evolution of body size: Consequences of an energetic definition of fitness. Am. Nat. 142:573-584.

Bulmer M. (1994). Theoretical evolutionary ecology. Sinauer Associates Publishers, Massachusetts.

Burger J. R., Hou C., Brown J. H. (2019). Towards a metabolic theory of life history. Proc. Nat. Acad. Sci. 116:26653-26661.

Calder W. A. I. (1984). Size, function, and life history. Harvard University Press, Cambridge.

Charlesworth B. (1980). Evolution in age-structured populations. Cambridge University Press, Cambridge.

Charlesworth B. (1994). Evolution in age-structured populations. 2nd edn. Cambridge University Press, Cambridge.

Charnov E. L. (1993). Life history invariants. Some explorations of symmetry in evolutionary ecology. Oxford University Press, New York.

Damuth J. (1981). Population density and body size in mammals. Nature 290:699-700.

Damuth J. (1987). Interspecific allometry of population density in mammals and other animals: the independence of body mass and population energy-use. Biol. J. Linnean Society. 31:193-246.

De Magalhães J. P. Costa J. (2009). A database of vertebrate longevity records and their relation to other life-history traits. J. Evol. Biol. 22:1770-1774.

del Hoyo, J., Elliot, A., Sargatal, J., \& Christie, D. A., eds (1992-2011). Handbook of the birds of the world. Vol. 1-16. Lynx Edicions, Barcelona.
DeSante D. F. Kaschube D. R. (2009). The monitoring avian productivity and survivorship (MAPS) program 2004, 2005, and 2006 report. Bird Pop. 9:86-169.

Dunning J. B. (2007). Handbook of Avian Body Masses (2nd ed). CRC Press, Boca Raton.

Fenchel T. (1974). Intrinsic rate of natural increase: The relationship with body size. Oecologia 14:317-326.

Gill, F. \& Donsker, D., eds (2014). International Ornithological Committee World Bird List (v 4.4). doi:10.14344/IOC.ML.4.4.

Gompertz B. (1832). On the Nature of the Function Expressive of the Law of Human Mortality, and on a New Mode of Determining the Value of Life Contingencies. Phil. Trans. R. Soc. Lond. 123:513-585.

Griffiths D. (1977). Caloric variation in Crustacea and other animals. J. Anim. Ecol. 46:593-605.

Hudson L. N., Isaac N. J. B., Reuman D. C. (2013). The relationship between body mass and field metabolic rate among individual birds and mammals. J. Anim. Ecol. 82:1009-1020.

Humphries M. M. McCann K. S. (2014). Metabolic constraints and currencies in animal ecology. Metabolic ecology. J. Anim. Ecol. 83:7-19.

Jetz W., Sekercioglu C. H., Böhning-Gaese K. (2008). The worldwide variation in avian clutch size across species and space. PLOS Biol. 6:e303.

Jones K. E., Bielby J., Cardillo M., Fritz S. A., O'Dell J., Orme C. D. L., Safi K., Sechrest W., Boakes E. H., Carbone C., Connolly C., Cutts M. J., Foster K. J., Grenyer R., Habib M., Plaster C. A., Price S. A., Rigby E. A., Rist J., Teacher A., Binninda-Emonds O. R. P., Gittleman J. L., Mace G. M., Purvia A. (2009). PanTHERIA: a species-level database of life history, ecology, and geography of extant and recently extinct mammals. Ecology 90:2648.

Lotka A. J. (1922). Contribution to the energetics of evolution. Proc. Nat. Acad. Sci. 8:147-151.

Mahoney S. A. Jehl J. R. J. (1984). Body water content in marine birds. The Condor 86:208-209.

McCarthy M. A., Citroen R., McCall S. C. (2008). Allometric scaling and Bayesian priors for annual survival of birds and mammals. Am. Nat. 172:216-222.

McKechnie A. E. Wolf B. O. (2004). The allometry of avian basal metabolic rate: Good predictions need good data. Physiolo Biochem Zool 77:502-521.

McNab B. K. (2008). An analysis of the factors that influence the level and scaling of mammalian BMR. Comp. Bioch. Physiol. A 151:5-28.

Myhrvold N. P., Baldridge E. amd Chan B., Sivam D., Freeman D. L., Ernest S. K. M. (2015). An amniote lifehistory database to perform comparative analyses with birds, mammals, and reltiles. Ecology 96:3109.

Nasrinpour H. R., Reimer A. A., Friesen M. R., McLeod R. D. (2017). Data preparation for West Nile Virus agent-based modelling: protocol for processing bird 
population estimates and incorporating ArcMap in AnyLogic. JMIR Res Protoc 6:e138.

Odum E. P., Marshall S. G., Marples T. G. (1965). The caloric content of migrating birds. Ecology 46:901-904.

Odum H. T. Pinkerton R. C. (1955). Times speed regulator The optimum efficiency for maximum power output in physical and biological systems. Am. Sci. 43:331-343.

Peters R. H. (1983). The ecological implication of body size. Cambridge University Press, Cambridge.

Prothero J. W. (2015). The design of mammals. A scaling approach. Cambridge University Press, Cambridge.

Ricklefs R. E., Tsunekage T., Shea R. E. (2011). Annual adult survival in several new world passerine birds based on age ratios in museum collections. J. Ornithol. 152:481-495.

Roff D. A. (1992). The evolution of life histories. Theory and analysis. University of Chicago Press, New York.

Roff D. A. (2002). Life history evolution. Sinauer Associates, Inc., Massachusetts.

Santini L., Isaac N. J. B., Ficetola G. F. (2018). TetraDENSITY: A database of population density estmates in terrestrial vertebrates. Global Ecol. Biog. 27:787-791.

Schoener T. W. (1968). Sizes of feeding territories among birds. Ecology 49:123-131.

Smith F. A., Brown J. H., Haskell J. P., Alroy J., Charnov E. L., Dayan T., Enquist B. J., Ernest S. K. M., Hadly E. A., Jablonski D., Jones K. E., Kaufman D. M., Lyons S. K., Marquet P., Maurer B. A., Niklas K., Porter W., Roy K., Tiffney B., Willig M. R. (2004). Similarity of mammalian body size across the taxonomic hierarchy and across space and time. Am. Nat. 163:672-691.

Stearns S. C. (1992). The evolution of life histories. Oxford University Press, Oxford.

Stearns S. C. Hoekstra R. F. (2000). Evolution: an introduction. Oxford University Press, Oxford.

Tamburello N., Cote I. M., Dulvy N. K. (2015). Energy and the scaling of animal space use. Amazoniana 186:196211.

Tucker M. A., Ord T. J., Rogers T. L. (2014). Evolutionary predictors of mammalian home range size: body mass, diet and the environment. Global Ecol. Biog. 23:11051114.

Turner F. B., Jennrich R. I., Weintraub J. D. (1969). Home range and body size of lizards. Ecology 50:1076-1081.

Van Valen L. (1976). Energy and evolution. Evol. Theory 1:179-229.

Wilson, D. E. \& Mittermeier, R. A., eds (2009-2014). Handbook of the mammals of the world. Vol. 1-4. Lynx Edicions, Barcelona.

Wilson, D. E. \& Reeder, D. M., eds (2005). Mammals Species of the World. A Taxonomic and Geographic Reference (3rd ed). Johns Hopkins University Press, Baltimore.

Witting L. (1995). The body mass allometries as evolutionarily determined by the foraging of mobile organisms. J. theor. Biol. 177:129-137, https://doi.org/10.1006/jtbi.1995.0231.

Witting L. (1997). A general theory of evolution. By means of selection by density dependent competitive interactions. Peregrine Publisher, Århus, 330 pp, URL http://mrLife.org.

Witting L. (2002). From asexual to eusocial reproduction by multilevel selection by density dependent competitive interactions. Theor. Pop. Biol. 61:171-195, https://doi.org/10.1006/tpbi.2001.1561.

Witting L. (2008). Inevitable evolution: back to The Origin and beyond the 20th Century paradigm of contingent evolution by historical natural selection. Biol. Rev. 83:259-294, https://doi.org/10.1111/j.1469185X.2008.00043.x.

Witting L. (2017a). The natural selection of metabolism and mass selects allometric transitions from prokaryotes to mammals. Theor. Pop. Biol. 117:23-42, http://dx.doi.org/10.1016/j.tpb.2017.08.005.

Witting L. (2017b). The natural selection of metabolism and mass selects lifeforms from viruses to multicellular animals. Ecol. Evol. 7:9098-9118, http://dx.doi.org/10.1002/ece3.3432.

Witting L. (2021a). Behind the scene of body mass allometries. Preprint in prep for bioRxiv .

Witting L. (2021b). On the natural selection causality of bird life histories. Preprint in prep for bioRxiv .

Witting L. (2021c). Life history distributions reveal natural selection in birds and mammals. Preprint in prep for bioRxiv .

Witting L. (2021d). On the natural selection causality of mammal life histories. Preprint in prep for bioRxiv .

Witting L. (2021e). Selection-regulated population dynamic in birds and mammals. Preprint in prep for bioRxiv . 